Article

\title{
Epidemiology of Simultaneous Medullary and Papillary Thyroid Carcinomas (MTC/PTC): An Italian Multicenter Study
}

\author{
Marialuisa Appetecchia ${ }^{1, *}$, Rosa Lauretta ${ }^{1}$, Agnese Barnabei ${ }^{1}$, Letizia Pieruzzi ${ }^{2}$, \\ Irene Terrenato ${ }^{3}$, Elisabetta Cavedon ${ }^{4}$, Caterina Mian ${ }^{4}$, Maria Grazia Castagna ${ }^{5}$ and \\ Rossella Elisei ${ }^{2,+}$ on behalf of the SIE (Italian Society of Endocrinology) Working Group \\ 1 Oncological Endocrinology Unit, IRCCS Regina Elena National Cancer Institute, 00144 Rome, Italy; \\ rosalauretta@yahoo.it (R.L.); agnese.barnabei@ifo.gov.it (A.B.) \\ 2 Endocrinology Unit, University Hospital of Pisa, 56121 Pisa, Italy; pieruzziletizia@gmail.com (L.P.); \\ rossella.elisei@med.unipi.it (R.E.) \\ 3 Biostatistics-Scientific Direction, IRCSS Regina Elena National Institute, 00144 Rome, Italy; \\ irene.terrenato@ifo.gov.it \\ 4 Istituto Oncologico Veneto, University of Padua, 35100 Padua, Italy; elisabetta.cavedon@unipd.it (E.C.); \\ caterina.mian@unipd.it (C.M.) \\ 5 Endocrinology Unit, Policlinico S.M. alle Scotte, 53100 Siena, Italy; mariagraziacastagna@hotmail.com \\ * Correspondence: marialuisa.appetecchia@ifo.gov.it \\ + Listed in Appendix A.
}

Received: 11 September 2019; Accepted: 25 September 2019; Published: 9 October 2019

\begin{abstract}
Background: The concomitant presence of papillary thyroid cancer (PTC) and medullary TC (MTC) is rare. In this multicentric study, we documented the epidemiological characteristics, disease conditions and clinical outcome of patients with simultaneous MTC/PTC. Methods: We collected data of patients with concomitant MTC/PTC at 14 Italian referral centers. Results: In total, 183 patients were enrolled. Diagnosis was mostly based on cytological examination $(n=58,32 \%)$. At diagnosis, in the majority of cases, both PTC $(n=142,78 \%)$ and MTC $(n=100,54 \%)$ were at stage I. However, more cases of stage II-IV were reported with MTC (stage IV: $n=27,15 \%)$ compared with PTC ( $n=9$, $5 \%)$. Information on survival was available for 165 patients: 109 patients $(66 \%)$ were disease-free for both PTC and MTC at the last follow-up. Six patients died from MTC. Median time to progression was 123 months (95\% confidence interval (CI): 89.3-156.7 months). Overall, $45 \%$ of patients were disease-free after $>10$ years from diagnosis ( 125 months); this figure was $72.5 \%$ for PTC and $51.1 \%$ for MTC. Conclusions: When MTC and PTC are concurrent, the priority should be given to the management of MTC since this entity appears associated with the most severe impact on prognosis.
\end{abstract}

Keywords: medullary thyroid cancer; papillary thyroid cancer; epidemiology

\section{Introduction}

Papillary thyroid carcinoma (PTC) accounts for the wide majority (approximately 85\%) of thyroid cancers [1]. The incidence of this disease has largely increased over the last decades, primarily due to advances in diagnostic approaches [2]. According to current knowledge, PTC is an umbrella term that encompasses several tumor types with mutually exclusive mutations, in most cases $B R A F$ V600E, followed by RAS (15\%) and chromosomal rearrangements leading to the expression of the kinase domains of BRAF or of receptor tyrosine kinases, such as RET, NTRK, and ALK (12\%) [1]. Different mutations result in different disease behavior. However, most PTCs are clinically indolent, 
consistent with their simple genome characterized by few copy number alterations and a low mutational density $[1,3]$.

Medullary thyroid carcinoma (MTC) is another type of thyroid carcinoma. It is much rarer than PTC, accounting for 3-5\% of all thyroid cancers [1]. In three out of four patients, MTC is sporadic; less often, it represents the dominant component of the hereditary multiple endocrine neoplasia (MEN) type 2 syndromes, MEN2A and MEN2B. RET is the driver oncogene in MTC, followed by RAS mutations and RET or ALK fusions [4,5]. The clinical aggressiveness of MTC is related to RET mutation. When shared oncogenes between the two malignancies were sought, no common genetic alterations were found [6].

The concomitant presence of PTC and MTC is a rare event, described in the literature mainly in anecdotal reports [7-27], and in a few studies [6,28-32]. It is debated in the literature whether the concomitant presence in the same subject of PTC and MTC is random or whether it depends on a common gene alteration. More importantly, the clinical outcomes of patients with concurrent PTC and MTC require further investigation in a large sample of patients. In this multicenter study, we documented the epidemiological characteristics, disease conditions and clinical outcome of patients with simultaneous MTC/PTC.

\section{Patients and Methods}

\subsection{Study Setting and Design}

We collected data of patients with concomitant MTC/PTC diagnosed between 1992 and 2014 at 14 Italian referral centers located all over the country. Local Ethical Committees-Comitato Etico Centrale IRCCS Lazio Sez. IRCCS IFO-Fondazione G. B. Bietti-approved the study design on 12 July 2016 (approval code: RU/8684; ethic code: RS 827/16) and all patients had signed an informed consent to the use of their personal data for research purposes.

\subsection{Patients and Procedures}

Clinical charts of patients treated in the participating Centers from 1992 to 2014 were reviewed to identify those with concomitant MTC/PTC (foci had to be distinct in all cases). No other inclusion/exclusion criteria were applied. All patients were diagnosed and managed according to the standard practice of each center where they were followed.

For each patient with concomitant MTC/PTC, we reviewed demographic and clinical data (blood tests and imaging results), epidemiological characteristics, pathological conditions and clinical outcomes. For the staging of both PTC and MTC, the tumor, node and metastases (TNM 7th edition) staging system was applied.

Somatic and germline RET gene mutation data were collected, when possible (Sanger sequencing). Analysis was performed on both tissues and blood samples.

\subsection{Data Analysis}

We explored patients' and disease features at baseline, and between the same characteristics and clinical outcomes, in terms of metastatic status and progression-free survival (PFS; defined as the time from diagnosis to documented progression according to the RECIST criteria or death, whichever occurred first). Descriptive statistics were computed for all the variables of interest. PFS was evaluated according to the Kaplan-Meier product-limit method. Stratified analysis by specific demographic and pathological characteristics were also conducted, overall and for both PTC and MTC. Associations between variables were evaluated by Pearson's Chi-Square test. $p<0.05$ was considered statistically significant. All the statistical analyses were carried out using SPSS software (SPSS version 21.0, IBM, Armonk, NY, USA). 


\section{Results}

\subsection{Patients}

In total, 183 patients were enrolled (mean age: $56 \pm 13$ years; range: $16-84$ years; 39 (21\%) aged $\leq 45$ years; 105 (58\%) females). Table 1 depicts their baseline characteristics, including laboratory examinations, respectively; Table S1 lists oncological comorbidities. Suspicious diagnosis was mostly based on cytological examination ( $n=58,32 \%$; examination was decided due to medullary carcinoma in 20 cases and to papillary carcinoma in 38), followed by cytological examination + basal calcitonin (BCT) and BCT only ( $n=39$ each; 21\%). One-third of patients who underwent surgical procedure were submitted to total thyroidectomy with a central lymph node dissection (33\%). Overall, 44\% of patients $(n=81)$ were positive for pre-surgery anti-thyroglobulin antibodies and $14 \%(n=25)$ for anti-thyroperoxidase antibodies (AbTPO). Diagnosis was then confirmed by histological examination in all cases.

Table 1. Baseline characteristics of the 183 patients.

\begin{tabular}{|c|c|c|}
\hline \multirow{2}{*}{$\mathbf{N}^{\circ}$ of Cases } & $N$ & $\%$ \\
\hline & \multicolumn{2}{|l|}{183} \\
\hline Observed follow-up period (min-max); months & \multicolumn{2}{|c|}{$30(0-261)$} \\
\hline \multicolumn{3}{|l|}{ Age at diagnosis: (years): } \\
\hline - Mean (SD) & \multicolumn{2}{|c|}{$56.2(13.4)$} \\
\hline$-\leq 45$ years & 39 & 20 \\
\hline$->45$ years & 143 & 79 \\
\hline - Unknown & 1 & 1 \\
\hline \multicolumn{3}{|l|}{ Gender: } \\
\hline - Females & 105 & 58 \\
\hline - Males & 78 & 42 \\
\hline \multicolumn{3}{|l|}{ Circumstances of diagnosis: } \\
\hline - Fine needle aspiration cytology & 58 & 32 \\
\hline - Fine needle aspiration cytology + basal calcitonin & 39 & 21 \\
\hline - Basal calcitonin & 39 & 21 \\
\hline - Incidental & 19 & 10 \\
\hline - Family history & 5 & 3 \\
\hline - Family history + basal calcitonin & 2 & 1 \\
\hline - Unknown & 21 & 12 \\
\hline Presence of non-oncologic comorbidity: & $N$ & $\%$ \\
\hline - None & 13 & 7 \\
\hline - Osteoporosis/osteopenia & 11 & 6 \\
\hline - Surrenal/hypophysis adenomas & 5 & 3 \\
\hline - Other & 114 & 62 \\
\hline - Unknown & 40 & 22 \\
\hline \multicolumn{3}{|l|}{ Presence of oncologic comorbidity: } \\
\hline- Yes & 21 & 12 \\
\hline- No & 114 & 62 \\
\hline - Unknown & 40 & 22 \\
\hline
\end{tabular}


Table 1. Cont.

\begin{tabular}{|c|c|c|}
\hline \multirow{2}{*}{$\mathbf{N}^{\circ}$ of Cases } & $N$ & $\%$ \\
\hline & \multicolumn{2}{|l|}{183} \\
\hline \multicolumn{3}{|l|}{ Familiar thyroid diseases: } \\
\hline- Yes & 33 & 18 \\
\hline$-\mathrm{No}$ & 95 & 52 \\
\hline - Unknown & 55 & 30 \\
\hline \multicolumn{3}{|l|}{ Oncologic family history: } \\
\hline- Yes & 38 & 21 \\
\hline$-\mathrm{No}$ & 77 & 42 \\
\hline - Unknown & 68 & 37 \\
\hline \multicolumn{3}{|l|}{ Familiar thyroid cancer: } \\
\hline- Yes & 18 & 10 \\
\hline$-\mathrm{No}$ & 165 & 90 \\
\hline \multicolumn{3}{|l|}{ Thyroid goiter } \\
\hline- Yes & 98 & 54 \\
\hline$-\mathrm{No}$ & 61 & 33 \\
\hline - Unknown & 24 & 13 \\
\hline \multicolumn{3}{|l|}{ FT4 (free thyroxine): } \\
\hline - EU (euthyroidism) & 81 & 44 \\
\hline - EU in treatment & 4 & 2 \\
\hline - Hypothyroidism & 3 & 2 \\
\hline - Hyperthyroidism & 13 & 7 \\
\hline - Unknown & 82 & 45 \\
\hline Pre-surgical calcitonin (ng/L), mean (SD) & $\begin{array}{c}699.2 \\
(1557.0)\end{array}$ & \\
\hline \multicolumn{3}{|l|}{ Pre-surgical anti-thyroglobulin antibodies } \\
\hline - Negative & 102 & 56 \\
\hline - Positive & 32 & 17 \\
\hline - Unknown & 49 & 27 \\
\hline \multicolumn{3}{|c|}{ Pre-surgical anti-thyroid peroxidase antibodies: } \\
\hline - Negative & 109 & 59 \\
\hline - Positive & 25 & 14 \\
\hline - Unknown & 49 & 27 \\
\hline
\end{tabular}

\subsection{Anatomo-Pathological Features Analysis}

Table 2 shows the pathological features of our series. At diagnosis, in the majority of cases, both PTC $(n=142,78 \%)$ and MTC $(n=100,54 \%)$ were at stage I of the disease (Table 2$)$; however, more cases of stage II-IV were reported with MTC (stage IV: $n=27,15 \%$, compared with nine cases, $5 \%$ for PTC). Median follow-up from diagnosis was 32 months (range: 0-261). 
Table 2. Tumor characteristics $(N=183)$.

\begin{tabular}{|c|c|c|}
\hline Tumor Characteristics & $N$ & $\%$ \\
\hline \multicolumn{3}{|l|}{ Histology: } \\
\hline - PTC classic variant + MTC & 77 & 42 \\
\hline - PTC follicular variant + MTC & 51 & 28 \\
\hline - PTC (other) + MTC & 55 & 30 \\
\hline \multicolumn{3}{|l|}{ Staging* of PTC: } \\
\hline-1 & 142 & 78 \\
\hline-2 & 8 & 4 \\
\hline-3 & 10 & 5 \\
\hline-4 & 9 & 5 \\
\hline - Unknown & 14 & 8 \\
\hline \multicolumn{3}{|l|}{ Staging* of MTC: } \\
\hline-1 & 100 & 54 \\
\hline-2 & 11 & 6 \\
\hline-3 & 27 & 15 \\
\hline-4 & 27 & 15 \\
\hline - Unknown & 18 & 10 \\
\hline \multicolumn{3}{|l|}{ PTC: } \\
\hline$-\mathrm{Tx}$ & 2 & 1 \\
\hline$-\mathrm{T} 1$ & 152 & 83 \\
\hline$-\mathrm{T} 2$ & 10 & 6 \\
\hline$-\mathrm{T} 3$ & 16 & 9 \\
\hline$-\mathrm{T} 4$ & 3 & 1 \\
\hline$-\mathrm{Nx}$ & 24 & 13 \\
\hline$-\mathrm{NO}$ & 136 & 74 \\
\hline$-\mathrm{N} 1-2$ & 23 & 13 \\
\hline$-M x$ & 48 & 26 \\
\hline$-\mathrm{M} 0$ & 134 & 73 \\
\hline$-\mathrm{M} 1$ & 1 & 1 \\
\hline \multicolumn{3}{|l|}{ MTC: } \\
\hline$-\mathrm{Tx}$ & 11 & 6 \\
\hline$-\mathrm{T} 1$ & 113 & 62 \\
\hline$-\mathrm{T} 2$ & 22 & 12 \\
\hline$-\mathrm{T} 3$ & 32 & 18 \\
\hline$-\mathrm{T} 4$ & 5 & 2 \\
\hline$-N x$ & 25 & 14 \\
\hline - N0 & 106 & 58 \\
\hline$-\mathrm{N} 1-2$ & 52 & 28 \\
\hline$-\mathrm{Mx}$ & 49 & 27 \\
\hline$-\mathrm{M} 0$ & 123 & 67 \\
\hline$-\mathrm{M} 1$ & 11 & 6 \\
\hline
\end{tabular}


Table 2. Cont.

\begin{tabular}{lcc}
\hline \multicolumn{1}{c}{ Tumor Characteristics } & $N$ & $\%$ \\
\hline PTC size: & 148 & 81 \\
\hline$-\leq 1 \mathrm{~cm}$ & 29 & 16 \\
\hline$->1 \mathrm{~cm}$ & 6 & 3 \\
\hline- Unknown & & \\
\hline MTC size: & 86 & 47 \\
\hline$-\leq 1 \mathrm{~cm}$ & 85 & 46 \\
\hline$->1 \mathrm{~cm}$ & 12 & 7 \\
\hline- Unknown & & 13 \\
\hline RET mutation: & 24 & 48 \\
\hline- Yes & 88 & 39 \\
\hline- No & 71 & \\
\hline- Unknown & & \\
\hline$*$ Anatomic stage according to the 7th Edition of AJCC staging system.
\end{tabular}

RET mutation was reported in 24 patients out of 112 in whom it was evaluated (21\%). The mutation was germinal in $5 / 24$ subjects $(21 \%)$ and somatic in the remaining 19 subjects. Table S2 displays the specific mutations in this gene: V804M was the most frequently reported $(n=8,33 \%)$.

\subsection{Clinical Outcomes}

Overall, 18 (9.8\%) patients were excluded from PFS analysis because they were lost to follow-up or it was not possible to give a final evaluation in terms of presence of disease due to lack of specific information for one of the two tumors. Therefore, 165 patients had available information about their overall survival (OS) and PFS status. Of these, 109 patients (60\%) were disease-free both for PTC and MTC at the last follow-up (Table 3). In the remaining $40 \%$ of cases, persistent/recurrent disease was reported (biochemical disease, loco-regional disease or distant metastases). Six patients died from MTC (one MTC stage IVa and five MTC stage IVc), and another patient died from pancreatic cancer; therefore, at the last follow-up, 158 (94\%) patients were alive.

Table 3. Clinical outcomes.

\begin{tabular}{lcc}
\hline \multicolumn{1}{c}{ Clinical Outcomes } & $\mathbf{N}$ & $\mathbf{\%}$ \\
\hline Overall cancer-specific survival outcome & & \\
\hline Disease free & 109 & 60 \\
\hline Biochemical disease & 32 & 18 \\
\hline Distant metastasis: & 10 & 5 \\
\hline - Locoregional disease & 8 & 4 \\
\hline - Death by MTC & 6 & 3 \\
\hline - Not evaluable & 18 & 10 \\
\hline PTC outcome & 143 & 78 \\
\hline Disease free & 17 & 9 \\
\hline Biochemical disease & 1 & 1 \\
\hline Distant metastasis & 1 & 1 \\
\hline Locoregional disease &
\end{tabular}


Table 3. Cont.

\begin{tabular}{lcc}
\hline \multicolumn{1}{c}{ Clinical Outcomes } & N & \% \\
\hline Not evaluable & 21 & 11 \\
\hline MTC outcome & & \\
\hline Disease free & 119 & 65 \\
\hline Biochemical disease & 24 & 13 \\
\hline Distant metastasis & 10 & 5 \\
\hline Locoregional disease & 7 & 4 \\
\hline Death by MTC & 6 & 3 \\
\hline Not evaluable & 17 & 10 \\
\hline
\end{tabular}

The Kaplan-Meier method gave an estimated median time to progression equal to 123 months (95\% confidence interval (CI): 89.3-156.7 months) (Figure 1A). Overall, $45 \%$ of patients were disease-free after more than 10 years from diagnosis (125 months); this figure was $72.5 \%$ for PTC and $51.1 \%$ for MTC (Figure 1B,C).
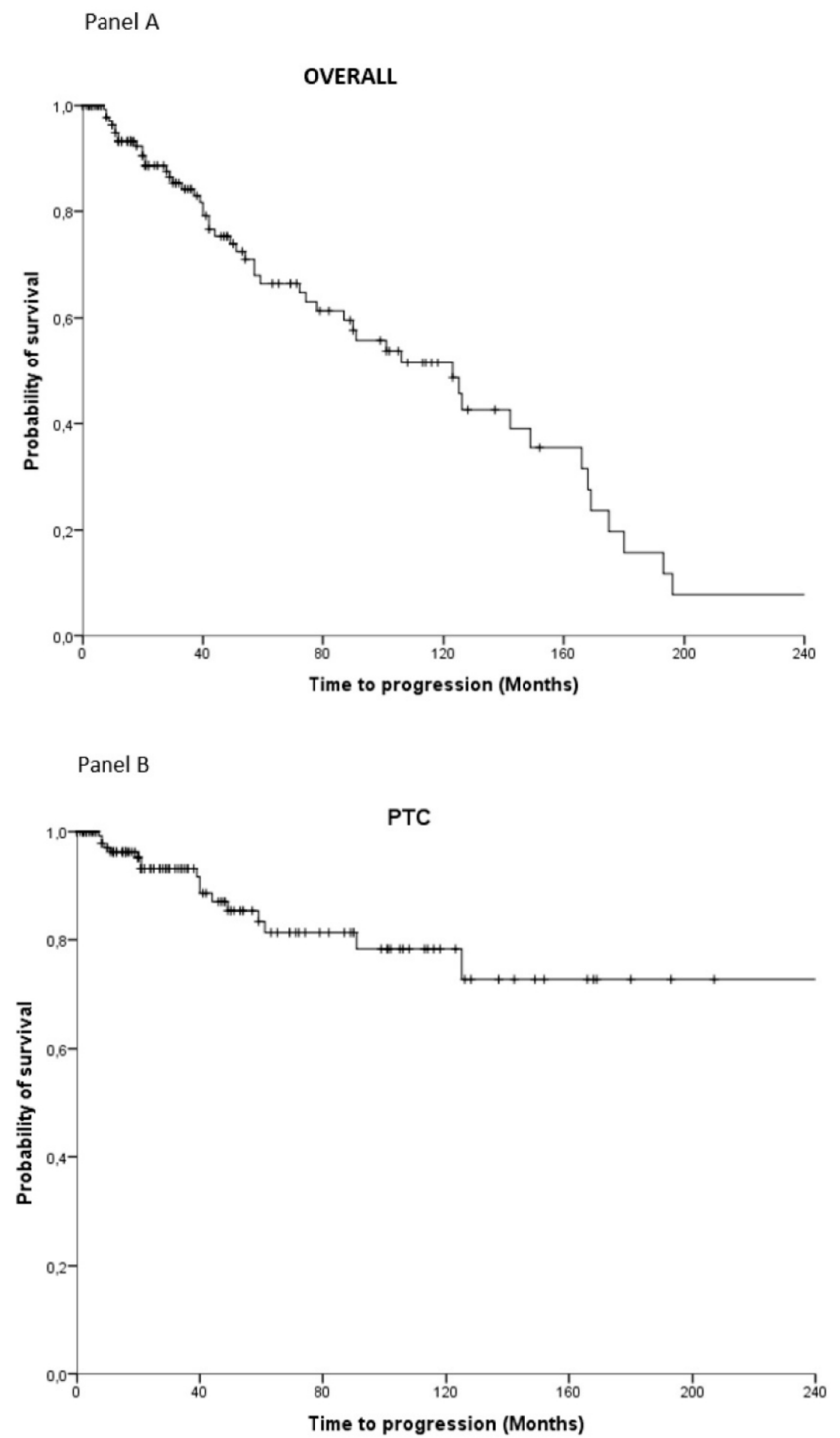

Figure 1. Cont. 


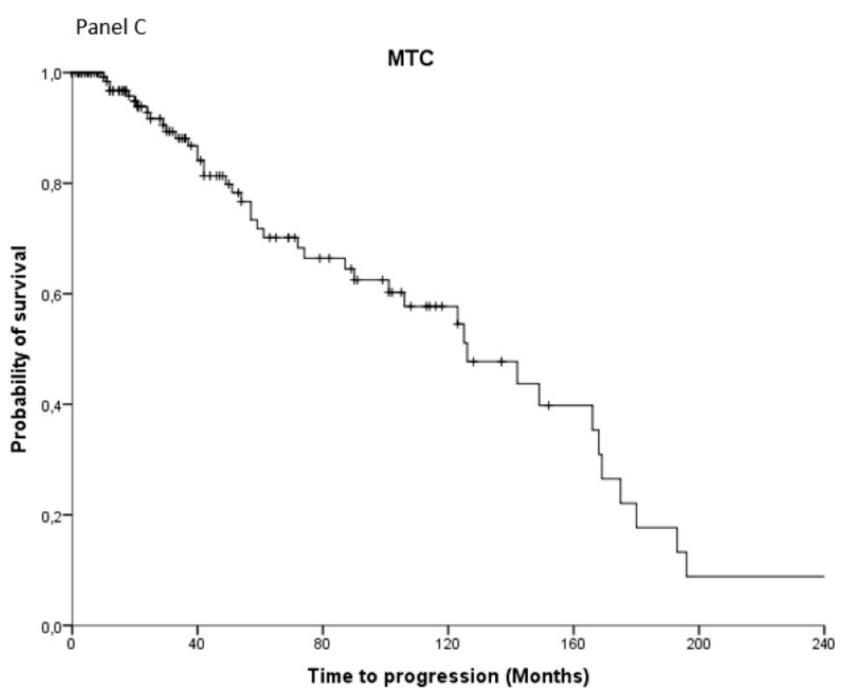

Figure 1. Overall progression-free survival (A) and specific progression-free survival for PCT (B) and $\operatorname{MTC}(\mathbf{C})$ only.

\subsection{Kaplan-Meier Stratified Analyses}

No differences were observed in conducting stratified analysis except for stage for specific MTC analysis (Figure S1, stage I + II median time to progression 175 months (95\% CI: 103.5-246.5) vs. stage III + IV 74 months (95\% CI: 14.6-133.4; $p<0.0001)$. Analysis of survival by tumor size is reported in Figure S1.

\section{Discussion}

The concomitant presence of PTC and MTC is a very rare event in clinical practice, and debate remains open as to whether this event should be considered coincidental or rather the result of a common genetic alteration [6]. Beside this—and possibly with greater relevance for clinical practice- the clinical outcomes of patients with concomitant PTC and MTC have only been poorly investigated, and only small series of patients were analyzed given the rarity of this occurrence [6,28-32].

In this Italian multicentric study, we investigated the epidemiological characteristics, disease conditions and clinical outcome in a large series of 183 patients with simultaneous MTC/PTC, and we were able to provide a picture of their characteristics. Remarkably, most patients were aged $\geq 45$ years, in line with a previous study, which suggested that patients with concomitant MTC/PTC are older than those with MTC alone [29] To our knowledge, this is one of the largest series, if not the largest, of subjects with concomitant MTC/PTC observed to date. Moreover, given the length of the follow-up (median follow-up, 32 months from diagnosis, with a maximum of 261 months, i.e. approximately 22 years), we were able to document the clinical outcomes of this population. However, we must acknowledge that the retrospective nature of our analysis hampers the results, especially due to the high number of missing data.

Although with these limitations, it appears that the prognosis of patients with concomitant MTC and PTC is good, with a $97 \%$ survival rate and a $66 \%$ of patients being progression-free at the last follow-up; $45 \%$ of patients were disease-free at more than 10 years from diagnosis. This finding is in line with a previous study, which show the relatively good prognosis of patients with simultaneous MTC/DTC compared to MTC only (10-year survival rates $87 \%$ vs. $81 \%$ ) [33]. Interestingly, the survival rates observed in our patient cohort were found to be lower compared to those reported in stage I sporadic MTC patients (i.e., 100\% at 10 years) [34]. Moreover, despite the pre-operative calcitonin levels were less than $10 \mathrm{pg} / \mathrm{mL}$ (levels associated with $97 \%$ survival rates at 10 years), only $45 \%$ were disease-free. Thus, the coexistence of both MTC and PTC might confer a worse prognosis compared to MTC only patients. Nevertheless, this hypothesis would require further investigation in a larger 
and more diverse population comprising MTC/PTC, MTC-only and PTC-only patients. Based on our preliminary observations, the prognosis appears driven by MTC. Out of the seven patients who died over the follow-up period, six MTC-related deaths were reported, all in patients with stage IV disease. Moreover, the Kaplan-Meier analysis showed that the overall progression pattern closely mirrors the pattern reported for MTC only. One can argue that this finding could be somehow expected, since MTC is a much more aggressive tumor than PTC. However, if MTC is early diagnosed, when it is still localized [35], we can expect to achieve surgical cure. From our data, the diagnosis of MTC was often performed too late, when the tumor was already not curable anymore. In our series, not all cases of MTC were diagnosed by measurement of serum calcitonin, that has been demonstrated to be more sensitive and specific than cytology [36]. Remarkably, as in the above-mentioned study series [6,28-32], in our series, 48 cases for sure, and likely also others among those for whom we missed the data, were submitted to an inadequate surgical treatment for MTC (i.e., total thyroidectomy alone without at least central compartment lymphadenectomy), which in many circumstances jeopardizes the cure of the patients.

RET is an oncogene involved in the development of sporadic and hereditary MTC while chromosomal translocations activating RET occur in $20-30 \%$ of patients with PTC. In our patient cohort, only 24 patients were harboring RET mutations and most of them, independently from the predominant histotype, were disease-free or with persistent disease. Our observations contrast with previous studies reporting that RET+ MTC were mostly associated with a worse prognosis [37]. Moreover, the RET mutation most frequently associated with the most aggressive behavior of the MTC, namely M918T, was found in only two patients.

In our analysis, we failed to identify any characteristic able to distinguish between MTC and PTC or to predict outcome, with the exception of MTC stage at diagnosis, with a more advanced stage being associated with higher risk of progression. Our finding seems consistent with the predictive relevance of stage at diagnosis reported in a small cohort of 19 patients with concurrent MTC/PTC [38]. Among the patients with recurrent disease, the subtype of recurrence was consistent with the preoperative diagnosis and with the subtype with the more advanced stage at the time of initial surgery. However, it should be noted that, in our patient population, most PTCs were at stage I and of classic and follicular variants, which are reported historically being low-risk subtypes [39]. Another relevant finding is the role of serum calcitonin evaluation, which helped us in the diagnosis of about $40 \%$ of cases.

\section{Conclusions}

Our study shows that, when MTC and PTC are concurrent in the same patient, the priority should be given to the management of MTC-however, according to the specific characteristics of the two tumors-since this entity appears to be the one with the most severe impact on prognosis. Since patients with concomitant MTC and PTC have one or more thyroid nodules, in their presurgical work up, calcitonin should be always included, even in the presence of an already positive cytology for PTC. Moreover, our findings further support the notion that the early diagnosis of MTC is still an unmet need both when it is isolated and when associated to another thyroid cancer such as PTC [38]. Further studies aimed at investigating the molecular signature of concomitant MTC and PTC may hold promise to pave the way for the identification of candidate target genes for therapy. Gene-expression sequencing and microarrays along with genome-wide association studies may aid in the identification of cancer-specific germline and somatic mutations, which can contribute to more sensitive diversification of cancer subtypes and facilitate early diagnosis. Collectively, genomics-driven approaches are expected to lead to a more personalized treatment for patients with simultaneous MTC/PTC.

Supplementary Materials: The following are available online at http://www.mdpi.com/2072-6694/11/10/1516/s1, Figure S1: Progression-free survival according to MTC stage, Table S1: Cancer sites of the 21 patients with concomitant cancer, Table S2: Different RET mutations. 
Author Contributions: Conceptualization, M.A., R.L. and R.E.; Methodology, M.A. and R.L.; Formal Analysis, I.T.; Investigation, all; Writing-Original Draft Preparation, M.A. and R.L.; Writing-Review and Editing, All authors; and Supervision, M.A.

Funding: This research received no external funding.

Acknowledgments: The thank the Presidents of the Italian Society of Endocrinology during the activity of the Working Group, Professors Francesco Trimarchi, Andrea Lenzi, Paolo Vitti. Editorial assistance was provided by Aashni Shah and Chiara Degirolamo (Polistudium SRL, Milan, Italy). This assistance was supported by internal funds.

Conflicts of Interest: No competing financial interests exist.

\section{Appendix A}

The SIE (Italian Society of Endocrinology) Working Group: Stefano Mariotti, Laura Fugazzola, Fabio Orlandi, Cristina Romei, Fabiana Pani, Matilde Calanchini, Paola Loli, Paolo Limone, Ettore Seregni, Cosimo Durante, Andrea Maria Isidori, Dominique Van Doorne, Andrea Fabbri, Sebastiano Filetti, Furio Pacini, and Luca Giacomelli.

\section{References}

1. Fagin, J.A.; Wells, S.A., Jr. Biologic and clinical perspectives on thyroid cancer. N. Engl. J. Med. 2016, 375, 1054-1067. [CrossRef] [PubMed]

2. Davies, L.; Welch, H.G. Current thyroid cancer trends in the United States. JAMA Otolaryngol. Head Neck Surg. 2014, 140, 317-322. [CrossRef] [PubMed]

3. Lawrence, M.S.; Stojanov, P.; Polak, P.; Kryukov, G.V.; Cibulskis, K.; Sivachenko, A.; Carter, S.L.; Stewart, C.; Mermel, C.H.; Roberts, S.A.; et al. Mutational heterogeneity in cancer and the search for new cancer-associated genes. Nature 2013, 499, 214-218. [CrossRef] [PubMed]

4. Grubbs, E.G.; Ng, P.K.S.; Bui, J.; Busaidy, N.L.; Chen, K.; Lee, J.E.; Lu, X.; Lu, H.; Meric-Bernstam, F.; Mills, G.B.; et al. RET fusion as a novel driver of medullary thyroid carcinoma. J. Clin. Endocrinol. Metab. 2015, 100, 788-793. [CrossRef] [PubMed]

5. Moura, M.M.; Cavaco, B.M.; Leite, V. RAS proto-oncogene in medullary thyroid carcinoma. Endocr. Relat. Cancer 2015, 22, R235-R252. [CrossRef] [PubMed]

6. Ciampi, R.; Romei, C.; Pieruzzi, L.; Tacito, A.; Molinaro, E.; Agate, L.; Bottici, V.; Casella, F.; Ugolini, C.; Materazzi, G.; et al. Classical point mutations of RET, BRAF and RAS oncogenes are not shared in papillary and medullary thyroid cancer occurring simultaneously in the same gland. J. Endocrinol. Investig. 2017, 40, 55-62. [CrossRef] [PubMed]

7. Ishida, T.; Kawai, T.; Iino, Y.; Shinozaki, K.; Oowada, S.; Izuo, M. Concurrent medullary carcinoma adjacent to papillary carcinoma of the thyroid-A clinicopathological and electron microscopic study. Gan No Rinsho. 1985, 31, 1814-1820.

8. Meinhard, K.; Michailov, I. Simultaneous occurrence of medullary and papillary carcinoma in the same thyroid lobe. Zentralbl. Pathol. 1995, 140, 459-464.

9. Kobayashi, K.; Teramoto, S.; Maeta, H.; Ishiguro, S.; Mori, T.; Horie, Y. Simultaneous occurrence of medullary carcinoma and papillary carcinoma of the thyroid. J. Surg. Oncol. 1995, 59, 276-279. [CrossRef]

10. Darwish, A.; Satir, A.A.; Hameed, T.; Malik, S.; Aqel, N. Simultaneous medullary carcinoma, occult papillary carcinoma and lymphocytic thyroiditis. Malays. J. Pathol. 1995, 17, 103-107.

11. Pastolero, G.C.; Coire, C.I.; Asa, S.L. Concurrent medullary and papillary carcinomas of thyroid with lymph node metastases. A collision phenomenon. Am. J. Surg. Pathol. 1996, 20, 245-250. [CrossRef] [PubMed]

12. Tseleni-Balafouta, S.; Grigorakis, S.I.; Alevizaki, M.; Karaiskos, C.; Davaris, P.; Koutras, D.A. Simultaneous occurrence of a medullary and a papillary thyroid carcinoma in the same patient. Gen. Diagn. Pathol. 1997, 142, 371-374. [PubMed]

13. Kösem, M.; Kotan, C.; Algün, E.; Topal, C. Simultaneous occurrence of papillary intrafollicular and microcarcinomas with bilateral medullary microcarcinoma of the thyroid in a patient with multiple endocrine neoplasia type 2A: Report of a case. Surg. Today 2002, 32, 623-628. [CrossRef] [PubMed] 
14. Behrand, M.; von Wasielewski, R.; Brabant, G. Simultaneous medullary and papillary microcarcinoma of thyroid in a patient with secondary hyperparathyroidism. Endocr. Pathol. 2002, 13, 65-73. [CrossRef] [PubMed]

15. Merchant, F.H.; Hirschowitz, S.L.; Cohan, P.; Van Herle, A.J.; Natarajan, S. Simultaneous occurrence of medullary and papillary carcinoma of the thyroid gland identified by fine needle aspiration. A case report. Acta Cytol. 2002, 46, 762-766. [CrossRef] [PubMed]

16. Bocian, A.; Kopczyñski, J.; Rieske, P.; Piaskowski, S.; Sluszniak, J.; Kupnicka, D.; GóŸd̈̈, S.; Kowalska, A.; Sygut, J. Simultaneous occurrence of medullary and papillary carcinomas of the thyroid gland with metastases of papillary carcinoma to the cervical lymph nodes and the coinciding small B-cell lymphocytic lymphoma of the lymph nodes-A case report. Pol. J. Pathol. 2004, 55, 23-30.

17. Cupisti, K.; Raffel, A.; Ramp, U.; Wolf, A.; Donner, A.; Krausch, M.; Eisenberger, C.F.; Knoefel, W.T. Synchronous occurrence of a follicular, papillary and medullary thyroid carcinoma in a recurrent goiter. Endocr. J. 2005, 52, 281-285. [CrossRef]

18. Rossi, S.; Fugazzola, L.; De Pasquale, L.; Braidotti, P.; Cirello, V.; Beck-Peccoz, P.; Bosari, S.; Bastagli, A. Medullary and papillary carcinoma of the thyroid gland occurring as a collision tumour: Report of three cases with molecular analysis and review of the literature. Endocr. Relat. Cancer 2005, 12, 281-289. [CrossRef]

19. Younes, N.; Shomaf, M.; Al Hassan, L. Simultaneous medullary and papillary thyroid carcinoma with lymph node metastasis in the same patient: Case report and review of the literature. Asian J. Surg. 2005, 28, 223-226. [CrossRef]

20. Giacomelli, L.; Guerriero, G.; Falvo, L.; Altomare, V.; Chiesa, C.; Ferri, S.; Stio, F. Simultaneous occurrence of medullary carcinoma and papillary microcarcinoma of thyroid in a patient with MEN 2A syndrome. Report of a case. Tumori 2007, 93, 109-111. [CrossRef]

21. Dionigi, G.; Castano, P.; Bertolini, V.; Boni, L.; Rovera, F.; Tanda, M.L.; Capella, C.; Bartalena, L.; Dionigi, R. Simultaneous medullary and papillary thyroid cancer: Two case reports. J. Med. Case Rep. 2007, 1, 133. [CrossRef] [PubMed]

22. Di, F.M.; Sorrenti, S.; Palermo, S.; De, M.S.; Biancafarina, A.; Di, L.B.; Savino, G.; Giusti, D.; Casalvieri, L.; Catania, A. Two cases of synchronous papillary and medullary thyroid carcinoma. G. Chir. 2008, 29, 159-161.

23. Gul, K.; Ozdemir, D.; Ugras, S.; Inancli, S.S.; Ersoy, R.; Cakir, B. Coexistent familial nonmultiple endocrine neoplasia medullary thyroid carcinoma and papillary thyroid carcinoma associated with RET polymorphism. Am. J. Med. Sci. 2010, 340, 60-63. [CrossRef] [PubMed]

24. Costanzo, M.; Marziani, A.; Papa, V.; Arcerito, M.C.; Cannizzaro, M.A. Simultaneous medullary carcinoma and differentiated thyroid cancer. Case report. Ann. Ital. Chir. 2010, 81, 357-360. [PubMed]

25. Kataria, K.; Yadav, R.; Sarkar, C.; Karak, A.K. Simultaneous medullary carcinoma, papillary carcinoma and granulomatous inflammation of the thyroid. Singap. Med. J. 2013, 54, e146-e148. [CrossRef] [PubMed]

26. Erhamamci, S.; Reyhan, M.; Kocer, N.E.; Nursal, G.N.; Torun, N.; Yapar, A.F. Simultaneous occurrence of medullary and differentiated thyroid carcinomas. Report of 4 cases and brief review of the literature. Hell. J. Nucl. Med. 2014, 17, 148-152. [PubMed]

27. Mazeh, H.; Orlev, A.; Mizrahi, I.; Gross, D.J.; Freund, H.R. Concurrent medullary, papillary, and follicular thyroid carcinomas and simultaneous Cushing's syndrome. Eur. Thyroid J. 2015, 4, 65-68. [CrossRef] [PubMed]

28. Shifrin, A.L.; Xenachis, C.; Fay, A.; Matulewicz, T.J.; Kuo, Y.H.; Vernick, J.J. One hundred and seven family members with the rearranged during transfection V804M proto-oncogene mutation presenting with simultaneous medullary and papillary thyroid carcinomas, rare primary hyperparathyroidism, and no pheochromocytomas: Is this a new syndrome-MEN 2C? Surgery 2009, 146, 998-1005.

29. Kim, W.G.; Gong, G.; Kim, E.Y.; Kim, T.Y.; Hong, S.J.; Kim, W.B.; Shong, Y.K. Concurrent occurrence of medullary thyroid carcinoma and papillary thyroid carcinoma in the same thyroid should be considered as coincidental. Clin. Endocrinol. 2010, 72, 256-263. [CrossRef]

30. Shifrin, A.L.; Ogilvie, J.B.; Stang, M.T.; Fay, A.M.; Kuo, Y.H.; Matulewicz, T.; Xenachis, C.Z.; Vernick, J.J. Single nucleotide polymorphisms act as modifiers and correlate with the development of medullary and simultaneous medullary/papillary thyroid carcinomas in 2 large, non-related families with the RET V804M proto-oncogene mutation. Surgery 2010, 148, 1274-1280. [CrossRef]

31. Machens, A.; Dralle, H. Simultaneous medullary and papillary thyroid cancer: A novel entity? Ann. Surg. Oncol. 2012, 19, 37-44. [CrossRef] [PubMed] 
32. Biscolla, R.P.; Ugolini, C.; Sculli, M.; Bottici, V.; Castagna, M.G.; Romei, C.; Cosci, B.; Molinaro, E.; Faviana, P.; Basolo, F.; et al. Medullary and papillary tumors are frequently associated in the same thyroid gland without evidence of reciprocal influence in their biologic behavior. Thyroid 2004, 14, 946-952. [CrossRef] [PubMed]

33. Wong, R.L.; Kazaure, H.S.; Roman, S.A.; Sosa, J.A. Simultaneous medullary and differentiated thyroid cancer: A population-level analysis of an increasingly common entity. Ann. Surg. Oncol. 2012, 19, 2635-2642. [CrossRef] [PubMed]

34. Wells, S.A., Jr.; Asa, S.L.; Dralle, H.; Elisei, R.; Evans, D.B.; Gagel, R.F.; Lee, N.; Machens, A.; Moley, J.F.; Pacini, F.; et al. Revised American Thyroid Association Guidelines for the Management of Medullary Thyroid Carcinoma. The American Thyroid Association Guidelines Task Force on Medullary Thyroid Carcinoma. Thyroid 2015, 25, 6. [CrossRef] [PubMed]

35. Gharib, H.; McConahey, W.M.; Tiegs, R.D.; Bergstralh, E.J.; Goellner, J.R.; Grant, C.S.; van Heerden, J.A.; Sizemore, G.W.; Hay, I.D. Medullary thyroid carcinoma: Clinicopathologic features and long-term follow-up of 65 patientstreated during 1946 through 1970. Mayo Clin. Proc. 1992, 67, 934-940. [CrossRef]

36. Essig, G.; Porter, K.; Schneider, D.; Debora, A.; Lindsey, S.; Busonero, G.; Fineberg, D.; Fruci, B.; Boelaert, K.; Smit, J.; et al. Fine needle aspiration and medullary thyroid carcinoma: The risk of inadequate preoperative evaluation and initial surgery when relying upon FNAB cytology alone. Endocr. Pract. 2013, 19, 920-927. [CrossRef] [PubMed]

37. Moura, M.M.; Cavaco, B.M.; Pinto, A.E.; Domingues, R.; Santos, J.R.; Cid, M.O.; Bugalho, M.J.; Leite, V. Correlation of RET somatic mutations with clinicopathological features in sporadic medullary thyroid carcinomas. Br. J. Cancer 2009, 100, 1777-1783. [CrossRef]

38. Beninato, T.; Kluijfhout, W.P.; Drake, F.T.; Shen, W.T.; Suh, I.; Duh, Q.-Y.; Clark, O.; Gosnell, J. Preoperative diagnosis predicts outcomes in patients with concurrent medullary and papillary thyroid carcinoma. World J. Endocr. Surg. 2017, 9, 94-99.

39. Henke, L.E.; Pfeifer, J.D.; Baranski, T.J.; DeWees, T.; Grigsby, P.W. Long-term outcomes of follicular variant vs classic papillary thyroid carcinoma. Endocr. Connect. 2018, 7, 1226-1235. [CrossRef]

(C) 2019 by the authors. Licensee MDPI, Basel, Switzerland. This article is an open access article distributed under the terms and conditions of the Creative Commons Attribution (CC BY) license (http://creativecommons.org/licenses/by/4.0/). 